\title{
Ionophorous Properties of SY-1 (20-Deoxysalinomycin) in Rat Liver Mitochondria ${ }^{\dagger}$
}

\author{
Yukio MiYaZAKI, Mitsuaki MitAnI and Noboru ŌTAKE* \\ Central Research Laboratories, Kaken Chemical Co., Ltd., 1-6-42, Jujodai, \\ Kita-ku, Tokyo 114, Japan *Institute of Applied Microbiology, \\ The University of Tokyo, Bunkyo-ku, Tokyo 113, Japan
}

Received June 30,1978

\begin{abstract}
SY-1 (20-deoxysalinomycin), a monocarboxylic polyether antibiotic closely related to salinomycin, caused a rapid release of previously accumulated alkali metal cations by valinomycin or monazomycin in rat liver mitochondria, and simultaneously reversed swelling of mitochondria.

With a strict specificity for substrate and cation, SY-1 exhibited a property of inhibiting mitochondrial functions such as substrate oxidation, oxidative phosphorylation and ATP hydrolysis induced by valinomycin or monazomycin. In comparative study with salinomycin, SY -1 was found to be more effective on the mitochondrial functions than salinomycin.

On the basis of the results so far obtained, the inhibitory effect of SY-1 on mitochondria is interpreted as a result of interaction with essential cations, especially with $\mathrm{K}^{+}$, in mitochondria.
\end{abstract}

As described in the preceding paper, ${ }^{1 /} \mathrm{SY}-1$ has been isolated as a concurrent minor component of salinomycin produced by Streptomyces albus ATCC 21838 and the structure has been established to be 20-deoxysalinomycin. Like salinomycin, SY-1 contains a unique tricyclic spiroketal ring system, a first recognized function in the molecule of natural products.

In view of the structure-activity relationships of the naturally occurring ionophores, especially, correlation of the mode of ion-trapping and biological activities, the effect of $\mathrm{SY}-1$ on mitochondrial functions have been investigated in comparison with salinomycin and the details are described herein.

\section{MATERIALS AND METHODS}

Chemicals. SY-1, salinomycin and monazomycin used in this work were stock samples in our laboratory. Valinomycin was commercial product (P-L. Biochemical Inc.). ATP and ADP were obtained from Shigma Chemical Co, and $\mathrm{P}^{32}$ from Japan Atomic Energy Research Institute. The antibiotics were used in a

$\uparrow$ Studies on the Ionophorous Antibiotics. Part 19. Part 18, see Reference 1). solution of ethanol, and substrates or nucleotides were adjusted to $\mathrm{pH} 7.4$ with triethanolamine.

Mitochondria. Mitochondria were prepared from liver of male rats, weighing 200 to $250 \mathrm{~g}$, according to the procedure by Johnson and Lardy. ${ }^{2)}$ Mitochondrial protein concentrations were measured by the method of Lowry et al. ${ }^{3)}$

Measurement of oxygen consumption and oxidative phosphorylation of mitochondria. A continuous recording of oxygen consumption of mitochondria was carried out with an apparatus of Clark-type oxygen electrode. Oxidative phosphorylation was measured as described in previous paper. ${ }^{4}$ ?

Measurement of potassium movement. The concentration of potassium was monitored with an Orion $\mathrm{K}^{+}$specific electrode (92-19).

Measurement of mitochondrial swelling and contraction. Mitochondial swelling and contraction cycles were studied in $3.0 \mathrm{ml}$ of incubation media detailed in the experiments by following the light-scattering changes at $515 \mathrm{~nm}$ with a Shimazu UV-200 recording spectrophotometer.

Measurement of ATPase activity in mitochondria. ATPase activity was determined by measuring inorganic phosphate release during $5 \mathrm{~min}$ incubation at $30^{\circ} \mathrm{C}$, according to the method of Ueda et al. ${ }^{5}$

Reaction mixture and experimental conditions are described in the figure legends. 


\section{RESULTS}

Effect of $S Y-1$ on potassium transport and lightscattering induced by valinomycin or monazomycin in mitochondria

Figure 1A shows the effect of $\mathrm{SY}-1$ on mitochondrial $\mathrm{K}^{+}$transport stimulated by
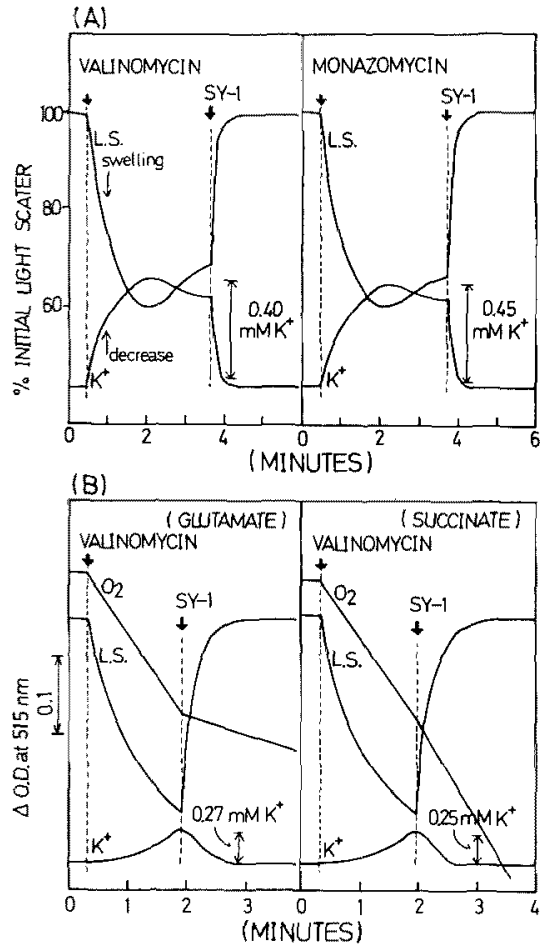

F1o. 1. (A) Effect of SY-1 on ATP-dependent Potassium Transport and Light-scattering Changes Induced by Valinomycin or Monazomycin in Rat Liver Mitochondria.

A downward defiection of the light scattering (L.S.) is associated with swelling of mitochondria. An upward deflection in the $\mathrm{K}^{+}$trace represents a decrease of its concentration in the medium or uptake of $\mathrm{K}^{+}$ by mitochondria. The reaction mixture contained $20 \mathrm{~mm}$ triethanolamine- $\mathrm{HCl}$, pH 7.4; $10 \mathrm{~mm}$ acetatetriethanolamine, pH 7.4;5 mM $\mathrm{MgCl}_{2} ; 5 \mathrm{mM} \mathrm{KCl}$; $5 \mathrm{~mm}$ Tris-ATP, pH 7.4;180 mM sucrose; and 3.8 to $4.8 \mathrm{mg}$ of mitochondrial protein. Final volume, $5 \mathrm{ml}$; temperature, $27^{\circ} \mathrm{C}$. Additions: valinomycin, $10^{-7} \mathrm{M}$; monazomycin, $10^{-7} \mathrm{M} ; \mathrm{SY}-1,1.3 \times 10^{-7} \mathrm{M}$,

(B) Effect of $S Y-1$ on substrate-dependent respiration, potassium transport, and light-scattering changes induced by valinomycin in mitochondria. The reaction mixture contained $20 \mathrm{mM} \mathrm{KCl} ; 5 \mathrm{mM} \mathrm{MgCl}$; $8 \mathrm{mM}$ Tris- $\mathrm{PO}_{4}, \mathrm{pH} 7.4 ; 10 \mathrm{~mm}$ Tris- $\mathrm{HCl}, \mathrm{pH} \mathrm{7.4}$; $10 \mathrm{~mm}$ substrate; $150 \mathrm{~mm}$ sucrose; $1.2 \mathrm{mg}$ of mitochondrial protein. Final volume, $3 \mathrm{mI}$; temperature, $27^{\circ} \mathrm{C}$. Additions: valinomycin, $10^{-7} \mathrm{M} ; \mathrm{SY}-1,1.3 \times$ $10^{-7} \mathrm{M}$. valinomycin and monazomycin in the presence of ATP. The addition of $10^{-7} \mathrm{M}$ valinomycin or $10^{-7} \mathrm{M}$ monazomycin was immediately followed by uptake of $\mathrm{K}^{+}$into mitochondria, and simultaneous decrease of the light-scattering (L.S.) produced by swelling of mitochondria. Subsequent addition of SY-1 $\left(1.3 \times 10^{-7} \mathrm{M}\right)$ caused a rapid loss of the previously accumulated $\mathrm{K}^{+}$and a contraction of mitochondria.

Meanwhile, when SY-1 was added in the medium before addition of valinomycin or monazomycin, $\mathrm{SY}-1$ inhibited the $\mathrm{K}^{+}$transport and mitochondrial swelling by the inducers. When glutamate or succinate was used as a energy source instead of ATP, valinomycin or monazomycin also induced the $\mathrm{K}^{+}$transport into the mitochondria, caused the swelling, and stimulated oxygen consumption (Fig. 1B). By subsequent addition of $\mathrm{SY}-1$, the accumulated $\mathrm{K}^{+}$was rapidly released, the decrease of light-scatter was also occurred, and the oxygen consumption due to glutamate oxidation was markedly inhibited, however, that due to succinate oxidation was unaffected by the antibiotic. The effect of SY-1 on the ATP and glutamate- or succinate-supported mitochondrial swelling coupled to ion transport is the evidence for the interaction with $\mathrm{K}^{+}$and the ion translocating mechanism of mitochondria.

\section{Effect of $S Y-1$ on substrate oxidation in mito- chondria}

The effect of $S Y-1$ on the respiration of state 4 or state 3 in mitochondria is shown in Table I. With a low concentration of $\mathrm{KCl}$ $(20 \mathrm{~mm})$ in the medium, SY-1 partially inhibited the state 4 respiration with glutamate, $\alpha$-ketoglutarate and malate plus pyruvate as substrate, however, no significant inhibition was observed with succinate and $\beta$-hydroxybutylate. Furthermore, the respiratory inhibition induced by $S Y-1$ was partially reversed at high concentration of $\mathrm{KCl}(75 \mathrm{~mm})$. A significant inhibition was observed when SY-1 was added to a ADP-activated oxidation with glutamate, $\alpha$-ketoglutarate or malate plus 
TABle I. InHIBITION OF SUbSTRATE-DEPENDENT RESPIRATION BY $S Y \rightarrow 1$

Reaction mixture contained $10 \mathrm{mM}$ Tris- $\mathrm{HCl}$, pH 7.4; $10 \mathrm{~mm}$ Tris- $\mathrm{PO}_{4}, \mathrm{pH} 7.4 ; 5 \mathrm{~mm} \mathrm{MgCl}_{2}$; $160 \mathrm{~mm}$ sucrose with $20 \mathrm{mM} \mathrm{KCl}$ or $100 \mathrm{~mm}$ sucrose with $75 \mathrm{mM} \mathrm{KCl} ; 5 \mathrm{mM}$ substrate; and 2 to $3 \mathrm{mg}$ of mitochondrial protein. Final volume, $3 \mathrm{ml}$; temperature, $27^{\circ} \mathrm{C}$. SY-1 was added at a concentration of $1.3 \times 10^{-6} \mathrm{M}$ for state 4 respiration and $10^{-7} \mathrm{M}$ for ADP-activated respiration.

\begin{tabular}{|c|c|c|c|}
\hline \multirow{3}{*}{ Substrate } & \multicolumn{3}{|c|}{ Inhibition $(\%)$ of respiration } \\
\hline & \multicolumn{2}{|c|}{ State 4} & \multirow{2}{*}{$\frac{\text { State } 3}{20 \mathrm{mM}} \frac{\mathrm{K}^{+}}{}$} \\
\hline & $20 \mathrm{mM}$ & $\begin{array}{c}75 \mathrm{mM} \\
\mathrm{K}^{+}\end{array}$ & \\
\hline Glutamate & 30 & 6 & 100 \\
\hline a-Ketoglutarate & 27 & 8 & 100 \\
\hline Malate - pyruvate & 16 & 5 & 56 \\
\hline$\beta$-Hydroxybutyrate & -16 & -18 & 18 \\
\hline Succinate & -14 & -16 & 10 \\
\hline
\end{tabular}

Table II. EFFect of SY-1 ON Substrate OXIDATION STIMULATEd by VARIOUS UNCOUPLING AGENTS

The reaction mixture was the same as described in Table I. Respiration was previously stimulated by the addition of valinomycin $\left(10^{-7} \mathrm{M}\right)$, monazomycin $\left(10^{-7} \mathrm{M}\right)$, and DNP $\left(2 \times 10^{-5} \mathrm{M}\right)$, then $\mathrm{SY}-1$ was added at a concentration of $10^{-6} \mathrm{M}$.

\begin{tabular}{lrrr}
\hline \multirow{1}{*}{ Substrate } & \multicolumn{3}{c}{ Inhibition $(\%)$} \\
\cline { 2 - 4 } & $\begin{array}{c}\text { Valino- } \\
\text { mycin }\end{array}$ & $\begin{array}{c}\text { Monazo- } \\
\text { mycin }\end{array}$ & DNP \\
\hline Glutamate & 87 & 88 & 95 \\
$\alpha$-Ketoglutarate & 74 & 86 & 93 \\
Malate+pyruvate & -35 & -22 & -15 \\
B-Hydroxybutyrate & -18 & -19 & -10 \\
Succinate & 0 & 3 & 5 \\
\hline
\end{tabular}

pyruvate. But the oxidation of succinate or $\beta$-hydroxybutyrate was appreciably affected by the antibiotic. Table II shows the degree to which SY-1 inhibited the various substrate oxidation previously stimulated by uncoupling agents such as valinomycin, monazomycin and 2,4-dinitrophenol (DNP). Under these conditions, SY-1 markedly inhibited the oxidation of glutamate or $\alpha$-ketoglutarate, whereas that of malate plus pyruvate or $\beta$-hydroxybutylate was slightly stimulated by the antibiotic. However, the inhibitory effect of SY-1 was also partially overcome at high concentration of $\mathrm{KCl}(75 \mathrm{~mm})$, for example, $87 \%, 88 \%$ or $95 \%$ inhibition by $\mathrm{SY}-1$ of glutamate oxidation stimulated by valinomycin, monazomycin and DNP were reduced to $54 \%, 56 \%$ and $65 \%$, respectively. The results suggest that the respiratory inhibition by SY-1 may be the result of loss of cation in mitochondria.

Effect of $S Y-1$ on substrate oxidation linked to alkali metal cation transport

Release of accumulated $\mathrm{K}^{+}$by SY-1 did not interfare with succinate oxidation (Fig. 1B). However, glutamate oxidation was affected by the antibiotic in proportion to the ability to inhibit alkali metal cation uptake in mitochondria. Figure 2 shows the remarkable ion specificity of $\mathrm{SY}-1$ and salinomycin for inhibiting glutamate oxidation stimulated by valinomycin or monazomycin. When valinomycin was used as inducer, $\mathrm{SY}-1$ specifically inhibited

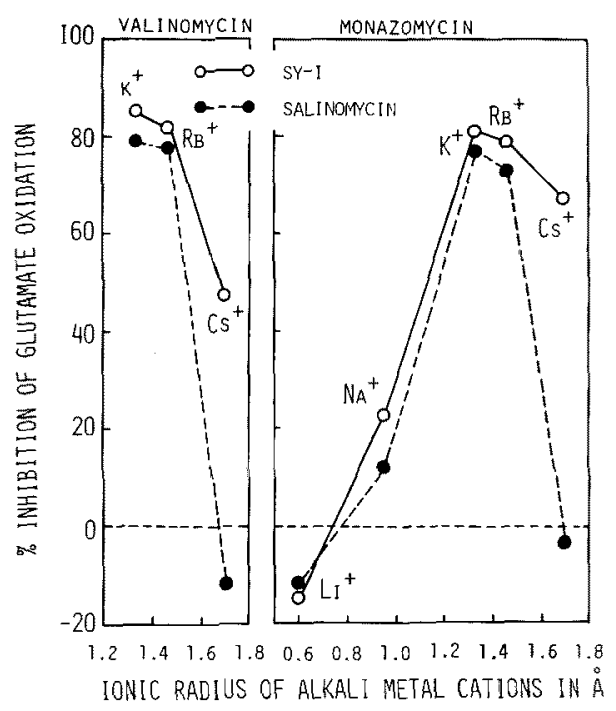

FIG. 2. Effect of Different Alkali Metal Cations on the Inhibition by $S Y-1$ or Salinomycin of Glutamate Oxidation Stimulated by Valinomycin and Monazomycin.

The reaction mixture contained $10 \mathrm{~mm}$ Tris- $\mathrm{HCl}$, pH 7.4; $10 \mathrm{~mm}$ Tris- $\mathrm{PO}_{4}$, pH 7.4; $5 \mathrm{mM} \mathrm{MgCl} ; 20 \mathrm{~mm}$ alkali metal cation ( $\mathrm{Cl}$ salt); $160 \mathrm{~mm}$ sucrose; and 2 to $3 \mathrm{mg}$ of mitochondrial protein. Final volume, $3 \mathrm{ml}$; temperature, $25^{\circ} \mathrm{C}$. Glutamate oxidation was previously stimulated by the addition of valinomycin or monazomycin at a concentration of $10^{-7} \mathrm{M}$, then $S Y-1$ or salinomycin were added at a concentration of $10^{-8} \mathrm{M}$ or $1.3 \times 10^{-8} \mathrm{M}$, respectively. 
the glutamate oxidation in $\mathrm{K}^{+}$or $\mathrm{Rb}^{+}$medium, and moderately in $\mathrm{Cs}^{+}$medium. Whereas salinomycin also inhibited in $\mathrm{K}^{+}$or $\mathrm{Rb}^{+}$ medium without affecting the oxidation coupled to $\mathrm{Cs}^{+}$transport. On the other hand, in monazomycin inducer, the glutamate oxidation coupled to $\mathrm{K}^{+}, \mathrm{Rb}^{+}, \mathrm{Cs}^{+}$or $\mathrm{Na}^{+}$ transport was inhibited by SY-1 with marked ion specificity. The sequence of ion selectivity of $\mathrm{SY}-1$ is as follows: $\mathrm{K}^{+}>\mathrm{Rb}^{+}>\mathrm{Cs}^{+}>$ $\mathrm{Na}^{+}>\mathrm{Li}^{+}$. Salinomycin also blocked the glutamate oxidation in a medium of $\mathrm{K}^{+}, \mathrm{Rb}^{+}$ or $\mathrm{Na}^{+}$. Furthermore, it is characteristic that SY-1 showed a greater ability to inhibit glutamate oxidation linked to $\mathrm{Cs}^{+}$transport than salinomycin.

\section{Effect of $S Y-1$ on ATP hydrolysis linked to alkali metal cation transport}

Like the pattern of ion specificity for inhibiting glutamate oxidation stimulated by valino-

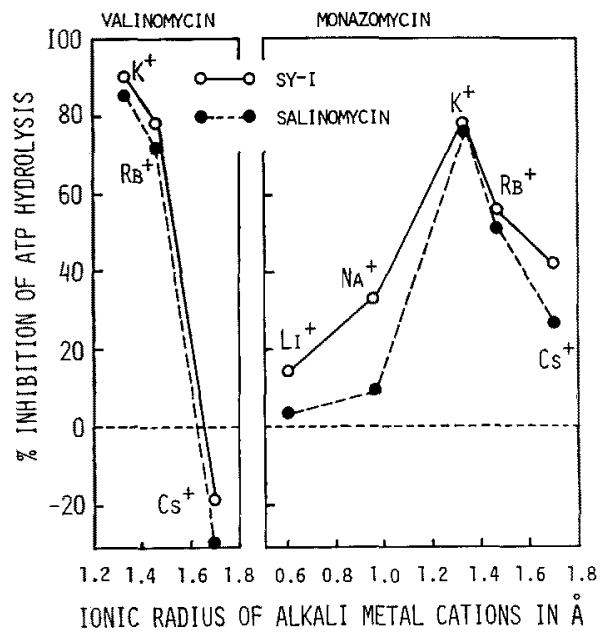

FIG. 3. Effect of Various Alkali Metal Cations on the Inhibition by SY-1 or Salinomycin of Mitochondrial ATPase Stimulated by Valinomycin or Monazomycin.

The reaction mixture contained $10 \mathrm{~mm}$ triethanolamine- $\mathrm{HCl}, \mathrm{pH} 7.4 ; 10 \mathrm{~mm}$ acetate-triethanolamine, pH 7.4; $20 \mathrm{~mm}$ alkali metal cation (Cl salt); $3 \mathrm{~mm}$ Tris-ATP, pH 7.4; $100 \mathrm{~mm}$ sucrose; and $0.3 \mathrm{mg}$ of mitochondrial protein. Final volume, $1 \mathrm{ml}$. Incubation was conducted for $5 \mathrm{~min}$ at $30^{\circ} \mathrm{C}$. Valinomycin was added at a concentration of $10^{-7} \mathrm{M}$, monazomycin at $8 \times 10^{-8} \mathrm{M}, \mathrm{SY}-1$ at $4 \times 10^{-7} \mathrm{M}$ and salinomycin at $1.3 \times 10^{-\theta} \mathrm{M}$. mycin (Fig. 2), the antibiotics SY-1 and salinomycin also inhibited hydrolysis of ATP in. duced by valinomycin or monazomycin with marked ion specificity. Figure 3 shows that when valinomycin induced the ATP hydrolysis, SY-1, like salinomycin, interfered the ATP hydrolysis in the presence of $\mathrm{K}^{+}$or $\mathrm{Rb}^{+}$, but not of $\mathrm{Cs}^{+}$. On the other hand, when the ATPase activity was stimulated by monazomycin, SY-1 inhibited this enzymatic activity in $\mathrm{K}^{+}(78 \%), \mathrm{Rb}^{+}(56 \%), \mathrm{Cs}^{+}(42 \%), \mathrm{Na}^{+}$ $(33 \%)$ and $\mathrm{Li}^{+}(14 \%)$. In contrast, the inhibitory values by salinomycin are as follows: $\mathrm{K}^{+}(76 \%), \mathrm{Rb}^{+}(51 \%), \mathrm{Cs}^{+}(27 \%), \mathrm{Na}^{+}(9 \%)$ and $\mathrm{Li}^{+}(3 \%)$.

\section{Effect of $S Y-1$ on oxidative phosphorylation in mitochondria}

It was observed that the phosphorylations coupled with oxidation of substrates were significantly inhibited by SY-1 without substrate specificity which observed for respiratory inhibition (Table III). The oxidative phosphorylations were more susceptible to the antibiotic than were ADP-activated respiration. Requirement of $\mathrm{K}^{+}$for generation of ATP in oxidative phosphorylation has been recognized for several years. ${ }^{8,7}$ ) Therefore, it seems reason-

\section{TABle IIT. EFFect OF SY-1 ON OXIDATIVE PhOSPHORYLATION IN MitochondRIA}

The reaction mixture contained $10 \mathrm{~mm}$ Tris- $\mathrm{HCl}$, pH 7.4; $5 \mathrm{mM} \mathrm{MgCl}_{2} ; 25 \mathrm{~mm} \mathrm{KCl} ; 150 \mathrm{~mm}$ sucrose; $10 \mathrm{~mm}$ substrate; $\mathrm{SY}-1,4 \times 10^{-7} \mathrm{M}$; and $1.3 \mathrm{mg}$ of mitochondrial protein. Final volume, $1 \mathrm{ml}$; temperature, $30^{\circ} \mathrm{C}$. Mitochondria were preincubated for 1 min with or without SY-1 before the addition of $2.5 \mathrm{~mm}$ ADP and $2.5 \mathrm{~mm}$ potassium phosphate( $\mathrm{pH} 7.4)$ labelled with ${ }^{32} \mathrm{P}$. After $1 \mathrm{~min}$ reaction, the initial rate of ATP synthesis was determined by the amount of ${ }^{32} \mathrm{P}$ incorporation into ATP.

\begin{tabular}{lrrr} 
Substrate & \multicolumn{1}{c}{$\begin{array}{c}\text { ATP synthesis } \\
\text { (nmol/mg } \\
\text { protein/min) }\end{array}$} & $\begin{array}{c}\text { Inhibi- } \\
\text { tion }\end{array}$ \\
\cline { 2 - 3 } & Control & SY-1 & $(\%)$ \\
\hline Glutamate & 115 & 0 & 100 \\
$\alpha$-Ketoglutarate & 93 & 0 & 100 \\
Malate+pyruvate & 96 & 11 & 88 \\
$\beta$-Hydroxybutyrate & 134 & 34 & 75 \\
Succinate & 161 & 42 & 74 \\
\hline
\end{tabular}


able to conclude that the inhibitory effect of SY-1 on the oxidative phosphorylation is the result of a loss of cation, particularly $\mathrm{K}^{+}$, in mitochondria.

\section{DISCUSSION}

SY-1 (20-deoxysalinomycin) is an antibiotic structurally related to salinomycin. Effect on mitochondrial functions and the structure-activity correlation of salinomycin have been extensively investigated in the previous papers, ${ }^{4,8}$ in which we demonstrated that the chemical modification of $\mathrm{C}-20$ hydroxyl group of salinomycin caused significant effects both on antimicrobial and ion transporting activities. Therefore, an investigation of the biological activity and ion transporting ability of SY-1 in connection with salinomycin is of great interest.

As described in the preceding paper, ${ }^{1 /} \mathrm{SY}-1$ was less active against gram-positive bacteria than salinomycin. On the other hand, the comparative studies of the effect of SY-1 on mitochondrial functions with that of salinomycin revealed that both antibiotics exhibited similar inhibitory properties which depend on substrate and cation. However, of considerable interest is SY-1, at low concentration, interacts with alkali metal cation translocating system of mitochondria. Figure 4 shows the inhibitory effects at various concentration of SY-1 and salinomycin on the state 3 respiration and valinomycin stimulated glutamate oxidation in mitochondria. The result indicates apparently that $S Y-1$ is about five to ten times more effective for inhibiting the ADP- or valinomycin-stimulated glutamate oxidation. Considering from the data, it seems likely that SY-1 is somewhat less polar than salinomycin and can easily diffuse across membranous barrier of mitochondria. This unique ability of SY-1 which interacts at low concentration with alkali metal cations would be expected as a powerful tool for investigating the ion translocating system is living cells.

In conclusion, on the basis of the foregoing results, the effect of SY-1 on mitochondrial

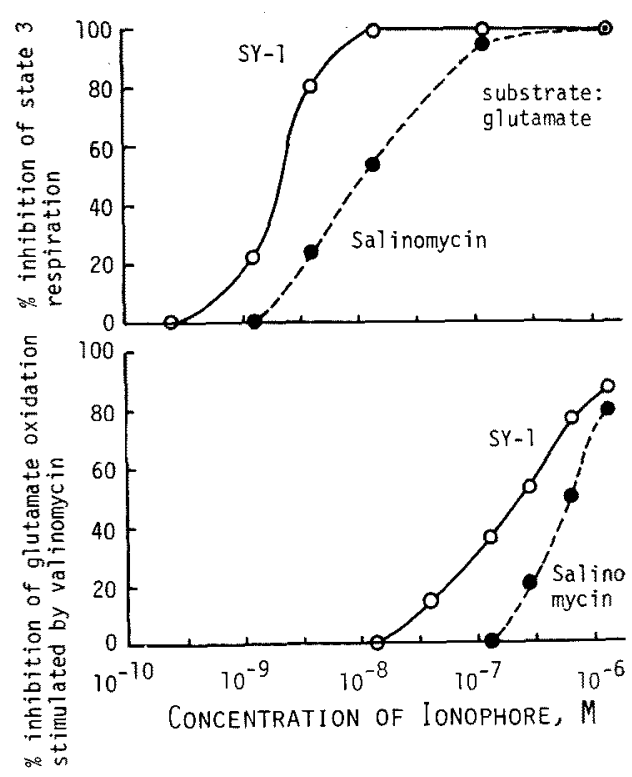

Fro. 4. Effect of at Various Concentration of SY-1 and Salinomycin on State 3 Respiration with Glutamate and Valinomycin Stimulated Glutamate Oxidation in Mitochondria.

The reaction mixtures and experimental conditions were the same as described in Table I and Table II, respectively.

functions is apparently arisen from the interaction with essential cations, especially with $\mathrm{K}^{+}$, in mitochondrial membrane and the effect of SY-1 was found to be more potent in comparison with salinomycin.

Acknowledgement. We are grateful to Professor Hiroshi Yonehara, The Institute of Applied Microbiology, University of Tokyo, for his helpful advices and discussions.

\section{REFERENCES}

1) Y. Miyazaki, A. Shibata, K. Tsuda, H. Kinashi and N. Otake, Agric. Biol. Chem., 42, 2129 (1978).

2) D. Johnson and H. Lardy, "Methods in enzymology," Vol. 10, 1967, p. 94.

3) O. H. Lowry, N. J. Rosebrough, A. Farr and P. J. Randall, J. Biol. Chem., 193, 256 (1951).

4) M. Mitani, T. Yamanishi, Y. Miyazaki and N. Otake, Antimicrob. Agents Chemother., 9, 655 (1976).

5) I. Ueda and T. Wada, Anal. Biochem., 37, 169 (1970).

6) P. D. Boyer, H. A. Lardy and P. H. Phillips, $J$. 
Biol. Chem., 146, 673 (1943).

7) B. C. Pressman and H. A. Lardy, ibid., 197, 547 (1952).
8) Y. Miyazaki, H. Kinashi, N. Otake, M. Mitani and T. Yamanishi, Agric. Biol. Chem., 40, 1633 (1976). 